\title{
Mesh opening effect on solid design and quality of screen printing in knit fabric
}

\begin{abstract}
Mesh opening effect on the design and quality of printed fabric in screen printing was investigated after printing solid design on knit fabric using different mesh count screens and different types of ink. The design effect was evaluated by visual assessment as well as microscopic observation. Mesh opening area of each screen type was calculated from respective digital microscope images to find the possibility of the amount of ink passing through the screen and level of print detail, produced in solid design on the screen. Also, print coverage, saw-tooth effect, line sharpness, etc. were examined by measuring different distances, angles etc. in printed fabric and were compared with image positives.
\end{abstract}

Keywords: mesh opening, mesh count, solid design, screen printing, printing quality
Volume 6 Issue 5 - 2020

\author{
Rasheda Begum Dina,' Md Zulhash Uddin, ${ }^{2}$ \\ Ummul Khair Fatema ${ }^{3}$ \\ 'Department of Wet Process Engineering, Bangladesh University \\ of Textiles, Bangladesh \\ ${ }^{2}$ Department of Wet Process Engineering, Bangladesh University \\ of Textiles, Bangladesh \\ ${ }^{3}$ Department of Environmental Science and Engineering, \\ Bangladesh University of Textiles, Bangladesh
}

\begin{abstract}
Correspondence: Rasheda Begum Dina, Assistant Professor, Department of Wet Process Engineering, Bangladesh University of Textiles,92, Shaheed Taj Uddin Ahmed Avenue, Tejgaon,Dhaka|208,Bangladesh, Tel +88019|35|8|37,

Email dina_butex@yahoo.com
\end{abstract}

Received: October 22, 2020 | Published: October 28, 2020
Abbreviations: MC, mesh count; GSM, gram per square meter, HW, high weight; LW, low weight

\section{Introduction}

Screen printing is one of the useful methods of printing designs in textiles. Screen printing is an extension of stenciling. "Resolution" refers to the level of printed detail in line and half-tone artwork that a given fabric is capable of reproducing. Primarily it is governed by the mesh count, and the relationship of thread diameter to mesh opening. ${ }^{1}$

Standard polyester fabrics make ideal stencil material for screen printing. Precision weaving techniques, using state-of-theart equipment optimized for screen printing applications, results in excellent fabric quality. Polyester fabrics woven from high-viscosity polyester are the further development of standard polyester fabrics. The material's reduced elasticity enhances the already good properties of standard fabrics. These stencil fabrics offer increased process reliability and significantly higher tensioning that is retained over large print runs and long periods of time.

Polyamide fabrics (nylon) have exceptional mechanical durability. This makes them highly suitable for printing abrasive media (ceramic colors, reflective inks). The stencil fabric's high elasticity makes it easier to print unevenly. The terms "mesh type" or "fabric number" are similar descriptions of the mesh count per centimeter / inch. ${ }^{2}$

Commonly, three types of textile inks are found. They are-traditional solvent-based inks, water-based inks and plastisol inks. Among these three, the water-based and plastisol inks are widely used in textile printing.

The solvent in solvent based ink has two primary functions that one to carry the ink to the substrate, and another is to evaporate quickly, leaving only the ink film on the substrate. While water is a solvent, the name solvent-based ink is used to describe a highly volatile solvent such as 2-butoxyethyl acetate, cyclohexanone and n-butyl acetate.
Solvent-based inks are considered the least environment-friendly due to the highly volatile solvents given off during printing and drying. The petroleum-based binder used in many solvent-based inks could be replaced with renewable resources such as vegetable oil or soy. The downsides are that the inks dry very slowly are less durable, and still contain solvents emitting VOCs during printing.

There are now inks on the market called eco-solvent inks. To most people, "eco" means ecological, and to be fair these inks are not as nasty as full solvent inks. But these inks generally contain glycol esters or glycol ether esters - both derived from mineral oil - hardly a renewable resource or an ecologically sound process.

Water-based inks use water as the main solvent. But that does not mean that water is the only solvent used. Many water-based inks contain "co-solvents" which may even be petroleum-based solvents. The reasons these co-solvents are used vary, but the main reason is to decrease the time and heat necessary to cure the ink on the fabric.

These inks are inexpensive and easy to manufacture.

Plastisol inks, commonly used for textile printing and especially for t-shirts, are a PVC-based ink composed of a clear, thick plasticizer fluid and PVC resin. The full name for PVC is polyvinyl chloride. The PVC life cycle results in the release of toxic, chlorine-based chemicals which end up as by-products such as carcinogenic and highly toxic dioxin and PCB. The major health concern about plastisol inks is not that they are PVC-based but that they contain phthalates. Phthalates are added to PVC plastics to transform a hard plastic into a soft, rubbery plastic by allowing the long polyvinyl molecules to slide against each other instead of rigidly binding together. ${ }^{3}$

Screen printing is one of the most cost-effective methods in today's printing market. The screen printing method has long been the standard for knit printing. This method is comparatively easier to print on whatever we want than other printing methods in comparison with time, cost, accuracy, production rate etc. However, for getting a 
correct design with proper print detail, resolution, coverage, hand feel etc., we should select the mesh count and ink system appropriately forgetting a specific type of design.

The amount of print paste passing through the screen can be controlled by the mesh (threads/inch) of the screen fabric. Generally, a coarse mesh allows more paste to pass through than a fine one. ${ }^{4}$

In many screen-printed fabrics, the edges of the printed areas appear serrated, although they were smooth curves or straight lines at the color separation stage. This is known as the 'saw-tooth effect' and is an almost inevitable consequence of the design area consisting of a regular array of threads and spaces.

The research work was carried on printing under the different mesh count screen for solid design with different ink to relate the effect of mesh count on cotton knit printed fabric and assessment of printing quality.

\section{Materials and methods}

\section{Materials}

Fabrics: $100 \%$ cotton fabric of the $1 \times 1$ rib structure, GSM 200 and 180 were purchased from Micro Fiber Limited, Rambagh, Kutubpur, Fatullah, Naryanganj, Bangladesh. Fabric specifications are given in Table 2. Fabrics are pretreated in lab with the recipe given in Table 1a and Table1b. After pretreatment, fabrics were printed by the five different inks.

Printing inks: Five types of printing inks are used for the experiment. Three of these inks are water based, one is solvent based and another is plastisol based. Both solvent-based ink NYE 100 (black) and plastisol based ink ONP 124 (red, free from phthalate) are ready paste while rest of three inks named RYUDYE-W KN WHITE P-75 RYUDYE-W KN CLEAR P-76 (acrylic polymer), Stretch White 3011 (acrylic resin) Clear 301C-J-1 and NEWTEX BIF New (pigment printing agent) are not ready paste. All inks were taken from Dysin Chemicals Ltd. The printing recipes are given in Table 4.

Mesh fabrics: Polyester monofilament mesh fabric of plain weave with 43, 77 and 100 mesh count was purchased from Dysin-Chem Limited, Dhaka, Bangladesh. A screen printing frame consists of an aluminum frame stretched with mesh fabric on it. Aluminum frame was stretched with polyester mesh fabric on it by a pneumatic system for making a flat screen. Solid designs were created on the types of mesh screen. Mesh specification is given in Table 3.

\section{Chemicals}

Pretreatment chemicals: Having purchased Standard soap, Sequestering Agent INSA, Wetting Agent KS-90, Hydrogen Peroxide, Stabilizer, Alkali, acetic acid, Enzyme-DL, Anti-Creasing Agent CAN; CBA, Per Oxide Killer OEM chemicals from Orient Chem -Tex Limited were used for scouring and bleaching of the fabrics before printing according to the recipe given in Table 1a and Table $1 \mathrm{~b}$.

Screen preparation chemicals: Emulsion photo cure TXR, Adhesive SFX001, and catalyst SFX002 AT were purchased from Dysin-Chem Limited. Emulsion photo cure TXR was used during the coating of screen mesh fabric and Adhesive SFX001 and catalyst SFX002 AT were used during attachment of mesh fabric with the aluminum frame.

\section{Instrumentation}

Screen stretcher machine: The pneumatic stretching machine made by Murakami, Singapore was used for stretching mesh fabric before attaching to the aluminum frame. The mechanical stretching apparatus produces tension forces in the warp and weft directions. Pneumatic screen stretcher delivers high-tension stretching on virtually any mesh/frame combination. Max Newton's air cylinders compensate for variations in mesh elasticity and fully extend after tensioning. Warp and weft were independently tensioned and controlled, and the durable PVC-coated locking bar grip tightly without tearing mesh.

Tension meter: A Murakami Tension Meter was used for recording tensions.

Screen drying machine: Screen Drying Machine, Murakami, was used for drying screen after emulsion coating.

UV exposure: Murakami, used for exposing UV light on the image positive paper was set on emulsion coated screen.

Screen printing machine: Screen printing machine, Ltd. Shenzhen China, was used for fabric printing.

Curing machine, NOR: was used for fixation of printing paste after printing process.

Viscometer: Viscometer, Brookfield, was used to measure the viscosity of printing paste.

Gyro wash machine: Gyro wash of James H. Heal Co. Ltd, Halifax, and English was used for wash fastness testing.

Light fastness tester: Microsol light fastness tester of James H.Heal, Halifax, England was used for light fastness testing.

Digital microscope: USB digital microscope, with high resolution image sensor, made in China, supplied from Dysin Chemicals Limited was used for observing the microscopic view of mesh screen, emulsion coated mesh fabric, and printed area of cotton fabric.

Lab temperature humidity control chamber: Fang Yuan Instrument Co. Ltd, Shenzhen, Chaina was used for conditioning printed sample.

\section{Methods}

Screen preparation: At first artwork or design was prepared. Solid designs were selected and their film positive was created. For solid design, 43, 77 and 100 mesh count screens were used. Tension is measured in Newton per $\mathrm{cm}(1 \mathrm{~N}=0.102 \mathrm{KP})$ with a tension meter placed on the mesh fabric. The screen was attached with a frame by adhesive SFX001 and catalyst SFX002 AT 17 Newton per cm.

Before coating the mesh, it was cleaned with a special screenprinting degreaser (screen solve) so that the emulsion sticks to it and dried at $55^{\circ} \mathrm{C}$ for five minutes. Screen was coated with photo cure TXR and dried, got film positive, aligned it to the screen, and exposed it with a screen-printing exposure unit for 20 seconds. The screen was hardened to light, but the positive or black area of the film blocked the light from reaching the emulsion, this left that area of the emulsion unexposed. After that screen was washed by normal water and dried at $55^{\circ} \mathrm{C}$.

Pre-treatment (scouring and bleaching): Cotton fabric was pretreated by the recipe given in Table 1.

Printing: Before printing, the screen and frame are lined with a tape. It was checked blocking out any unwanted 'pin-holes' in the emulsion. Fabrics were lightly gummed at the top of the printing plate. The screen was set on the machine. Printing paste was kept on the screen and the machine was switched on. Printing was done by 
constant squeeze pressure and $45^{\circ}$ squeeze angle. Thirty samples were prepared by three mesh screens; each screen was used to print on two types of fabric by five different print inks.

Curing: Curing was done at $150^{\circ} \mathrm{C}$ temperature for five minutes for fixation of printing ink.

Weight measurement: Printed and unprinted fabric was cut in a certain dimension for a specific design. The dimension was selected according to the printed area. Ink deposition weight was got by the difference of printed and unprinted fabric weight. All the weights were taken by electronic balance after conditioning the fabric for four hours at $65 \%$ relative humidity and $20^{\circ} \mathrm{C}$ temperatures.

Printed fabric analysis under digital microscope: At first, the Gaosuo software was installed on the computer from a CD. The digital microscope was kept with a stand and connected via wire to the USB port of the computer. A screen was opened ona computer. Before capturing picture, camera size was selected. There were five camera sizes. In the thesis work one camera size $(640 \times 480$ pixels $)$ was used. The printed fabric was kept under the microscope and clicked the capture option to capture the image. Capturing image was stopped after clicking on the stop option. The image was stored in the microscope and program files also. The captured picture was selected for measurement in turn. Distance, angles, etc. were measured by selecting different options of measurement. Then the picture was saved in the computer.

\section{Color fastness}

Washing fastness: Washing fastness test was carried out following ISO 105 C02 method. ${ }^{6}$

Light fastness test: Light fastness test was carried out by ISO 105B02 method. ${ }^{7}$
Table I Pretreatment recipe

\begin{tabular}{lcll}
\multicolumn{4}{l}{ Pretreatment (scouring and bleaching) } \\
\hline Chemical name & Dosing & Quantity & Fabric Wt.45.8kg \\
\hline KS-90 & $1.30 \mathrm{~g} / \mathrm{l}$ & $0.390 \mathrm{~kg}$ & \\
INSA & $0.25 \mathrm{~g} / \mathrm{l}$ & $0.075 \mathrm{~kg}$ & \\
CAN & $0.65 \mathrm{~g} / \mathrm{l}$ & $0.0195 \mathrm{~kg}$ & $98^{\circ} \mathrm{C}^{\prime} 50 \mathrm{Min}$ \\
CBA & $0.65 \mathrm{~g} / \mathrm{l}$ & $0.195 \mathrm{~kg}$ & \\
Stabilizer & $0.22 \mathrm{~g} / \mathrm{l}$ & $0.066 \mathrm{~kg}$ & \\
Caustic soda & $1.80 \mathrm{~g} / \mathrm{l}$ & $0.540 \mathrm{~kg}$ & \\
Hydrogen per oxide (50\%) & $1.75 \mathrm{~g} / \mathrm{l}$ & $0.525 \mathrm{~kg}$ &
\end{tabular}

Table 2 per oxide killing and enzyme treatment

\begin{tabular}{llll}
\hline Chemical name & Dosing & Quantity & Fabric Wt.45.8kg \\
\hline A.ACID & $0.80 \mathrm{~g} / \mathrm{I}$ & $0.24 \mathrm{~kg}$ & \\
OEN & $0.30 \mathrm{~g} / \mathrm{I}$ & $0.09 \mathrm{~kg}$ & \\
DL & $0.25 \mathrm{~g} / \mathrm{l}$ & $0.115 \mathrm{~kg}$ & \\
\hline
\end{tabular}

Table 3 Types of fabric with specification

\begin{tabular}{llll}
\hline Fabric & Knit structure & GSM & Composition \\
\hline HG & RIB $(|\times|)$ & 200 & $100 \%$ cotton \\
LG & RIB $(|\times|)$ & 180 & $100 \%$ cotton \\
\hline
\end{tabular}

Table 4 Types of mesh with specification

\begin{tabular}{llll}
\hline Mesh count & Weave & Filament type & Raw materials \\
\hline 43 & Plain & Mono & Polyester \\
77 & Plain & Mono & Polyester \\
100 & Plain & Mono & Polyester \\
\hline
\end{tabular}

Table 5 Printing recipe

\begin{tabular}{|c|c|c|c|}
\hline Ingredients & Ingredients composition & Used amount & Viscosity (cps) \\
\hline \multirow{4}{*}{ Water based ink } & RYUDYE-W KNWHITE & \multirow{4}{*}{$90 \%$} & \multirow{4}{*}{95000} \\
\hline & P-75 (=40\%) & & \\
\hline & RYUDYE-W KN CLEAR & & \\
\hline & P-76(=60\%) & & \\
\hline RYUDYE-W COLOUR & - & $10 \%$ & \\
\hline \multirow{3}{*}{ Water based ink } & Stretch White 30I-I $(=40 \%)$ and Clear $30 \mathrm{I}$ & \multirow{3}{*}{$90 \%$} & \multirow{3}{*}{130000} \\
\hline & & & \\
\hline & $C-J-1(=60 \%)$ & & \\
\hline Neo Color pigment & - & $8 \%$ & \\
\hline Fixer $F$ & - & $2 \%$ & \\
\hline \multicolumn{4}{|l|}{ (or Fixer N) } \\
\hline Water based ink (NEWTEX BIF) & - & $90 \%$ & 80000 \\
\hline Printing Color & - & $10 \%$ & \\
\hline Solvent based ink(NYEI00) & Ready paste & $100 \%$ & 7800 \\
\hline Plastisol based ink(ONP I24) & Ready paste & $100 \%$ & 200000 \\
\hline
\end{tabular}




\section{Results and discussions}

Calculation of open area percentage of mesh count fabric: It took $6 \times 6 \mathrm{~mm}^{2}$ area of mesh fabric for calculating the open area under the microscope at camera size $640 \times 480$ pixels. For every mesh count, the number of open rectangles was counted and the percentage of the open area was calculated by the following formula.

Average rectangle area $=\frac{\sum(\text { Total open rectangle area })}{(\text { number of open rectangle area })}$

$$
\text { Percentage of open area }=\frac{\text { Average rectangle area }}{36} \times 100
$$

Total open rectangle area $=$ average open rectangle area $\times$ total number of open rectangle area. The open area percentage for different mesh count is tabulated in Table 6 .

Table 6 Open area of mesh fabric in different screen count

\begin{tabular}{lllllll}
\hline $\begin{array}{l}\text { Mesh } \\
\text { count }\end{array}$ & $\begin{array}{l}\text { Total number of open } \\
\text { rectangles at 6 } \mathbf{6}^{\prime} \mathbf{6 \mathbf { m m } ^ { 2 }}\end{array}$ & $\begin{array}{l}\text { Average } \\
\text { rectangle area }\end{array}$ & $\begin{array}{l}\text { Total } \\
\text { area }\end{array}$ & $\begin{array}{l}\text { Percentage of Open } \\
\text { area }\end{array}$ & $\begin{array}{l}\text { Average yarn } \\
\text { width }\end{array}$ & $\begin{array}{l}\text { Average yarn } \\
\text { height }\end{array}$ \\
\hline 43 & 25 & 0.3938 & 9.845 & 27.34 & 0.488 & 0.64 \\
77 & 100 & 0.0509 & 5.059 & 14.04 & 0.193 & 0.243 \\
100 & 144 & 0.0394 & 5.673 & 15.75 & 0.173 & 0.226 \\
\hline
\end{tabular}

The order of percentage of open area was as below:

43 mesh count screen $>100$ mesh count screen $>77$ mesh count screen

In mesh count 43 (Figure 1a), there were five lines of open rectangles and each line had five open rectangles. In one line the area of open rectangles were as below:

$$
\text { The area of open rectangles }\left(\mathrm{mm}^{2}\right)
$$$$
\begin{array}{llll}
0.381 & 0.384 & 0.41 & 0.41
\end{array}
$$$$
0.384
$$

The average of open rectangles area was $0.3938 \mathrm{~mm}^{2}$ and total number of open rectangles was 25 . Total open area was $9.845 \mathrm{~mm}^{2}$.

In mesh count 77 (Figure 1b), there were ten lines of open rectangles and each line had ten open rectangles. In one line the area of open rectangles was as below:

\begin{tabular}{llllll}
\hline \multicolumn{6}{l}{ The area of open rectangles $\left(\mathrm{mm}^{2}\right)$} \\
0.058 & 0.04 & 0.067 & 0.056 & 0.067 & 0.056 \\
0.024 & 0.029 & 0.048 & 0.064 & & \\
\hline
\end{tabular}

The average of open rectangles area was $0.0509 \mathrm{~mm}^{2}$ and total number of open rectangles was 100 . Total open area was $5.09 \mathrm{~mm}^{2}$.

In mesh count100 (Figure 1c), there were twelve lines of open rectangles and each line had twelve open rectangles. In one line the area of open rectangles were as below:

\begin{tabular}{llllll}
\multicolumn{6}{l}{ The area of open rectangles $\left(\mathrm{mm}^{2}\right)$} \\
0.032 & 0.038 & 0.032 & 0.038 & 0.048 & 0.038 \\
0.038 & 0.038 & 0.04 & 0.038 & 0.048 & 0.045
\end{tabular}

The average of open rectangles area was $0.0394 \mathrm{~mm}^{2}$ and total number of open rectangles was 144.Total open area was $5.6736 \mathrm{~mm}^{2}$.

Visual assessment of printed fabric: For visual assessment, we categorized the printed fabric, excellent (rating-7), very good (rating-6), good (rating-5), moderate (rating-4), bad (rating-3), very bad (rating-2), worst (rating-1) in background coverage, hand feel, print detail and saw tooth effect (Table 7).

The ink was flooding through the large open area in the higher mesh opening screen, making the image blurry as the ink bleeds. The background coverage was good but lost print detail and also increased bad hand feelings (Figure 3) as the ink was deposited in a high percentage for higher mesh opening screen. From Figure 4, background coverage decreases with the increase of mesh opening area.

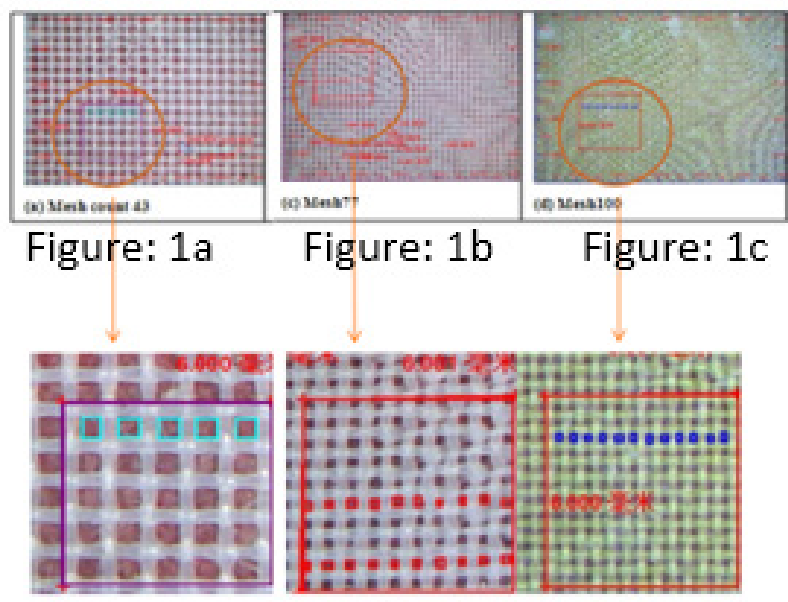

Images of mesh fabric uved in different screen (6400480 pixels $\& \times 25$ )

Figure I Images of mesh fabric used in different screen (at camera size $640 \times 480$ pixels).

\section{Ink deposition on printed fabric}

At first the printed and unprinted fabrics were conditioned for four hours at temperature $20^{\circ} \mathrm{C}$ and 65 percent relative humidity. Then the samples were cut with the same dimension for specific design and measured their weight by electronic balance. The sample size was $\left(10^{\prime \prime} \times 9^{\prime \prime}\right)$. The ink deposition percentage was calculated by the following formula-

$$
\text { Percentage of link deposition }=\frac{\text { printed fabric weight-unprinted fabric weight }}{\text { unprinted fabric weight }} \times 100 \%
$$

In Figure 5, it can be observed that ink was deposited higher percentage in high GSM fabric than lower GSM. The high viscous paste was deposited with more weight than lower viscous paste. The order was $\mathrm{ONP}>\mathrm{CJ}-1-301, \mathrm{SW}-1-301>\mathrm{P} 75, \mathrm{P} 76>$ Pigment $>\mathrm{NYE}$ from Figure 3 , it found that more paste was deposited on printed fabric by high open area mesh count screen as the more open area pass more ink. The order was $43 \mathrm{MC}$ screen $>100 \mathrm{MC}$ screen $>77 \mathrm{MC}$ screen. 
Table 7 Quality of solid printed fabric (visual assessment)

\begin{tabular}{llllll}
\hline Ink name & Mesh count & Background coverage & Print detail & Saw tooth effect & Hand feel \\
\hline P-75(40\%) & 43 & excellent & moderate & good & Very bad \\
P-76(60\%) & 77 & good & Very good & moderate & Bad \\
& 100 & very good & good & Very poor & Good \\
ONP-124 & 43 & Very good & moderate & good & Worst \\
& 77 & moderate & Very good & moderate & Very bad \\
& 100 & good & good & Very poor & Bad \\
NYE-100 & 43 & Very good & moderate & good & Bad \\
& 77 & moderate & Very good & moderate & Moderate \\
& 100 & good & good & Very poor & Good \\
$30 I-C-J-I(60 \%)$ & 43 & excellent & moderate & good & Very bad \\
$30 I-S W-I(40 \%)$ & 77 & good & Very good & moderate & Bad \\
& 100 & very good & good & Very poor & Good \\
Newtex BIF & 43 & Very good & moderate & good & Good \\
& 77 & Moderate & Very good & moderate & Very good \\
& 100 & Poor & good & Very poor & Excellent \\
\hline
\end{tabular}
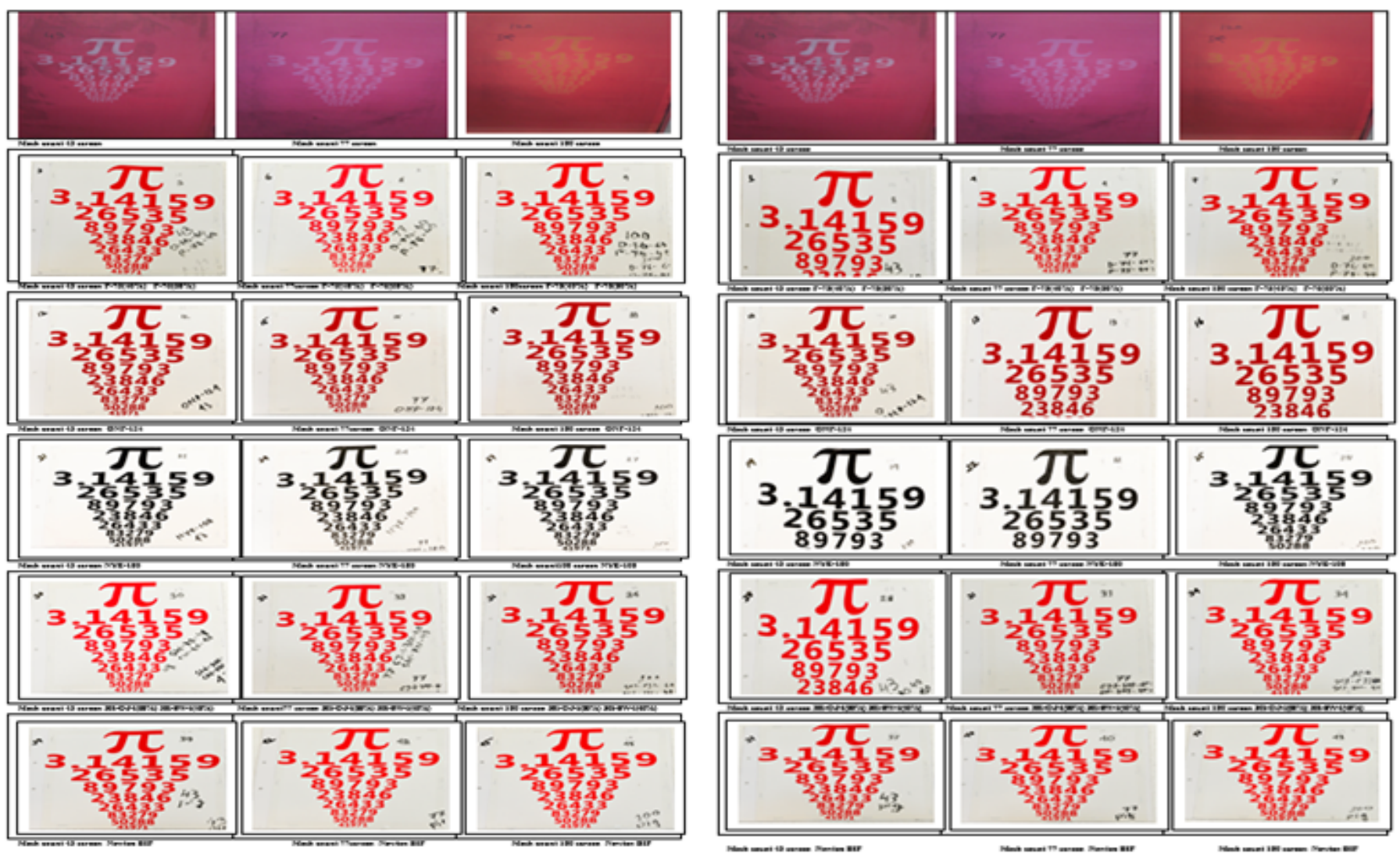

Figure 2a Solid design printed fabric (low GSM) with different mesh count screen by different inks.

Figure 2b Solid design printed fabric (high GSM) with different mesh count screen by different ink. 


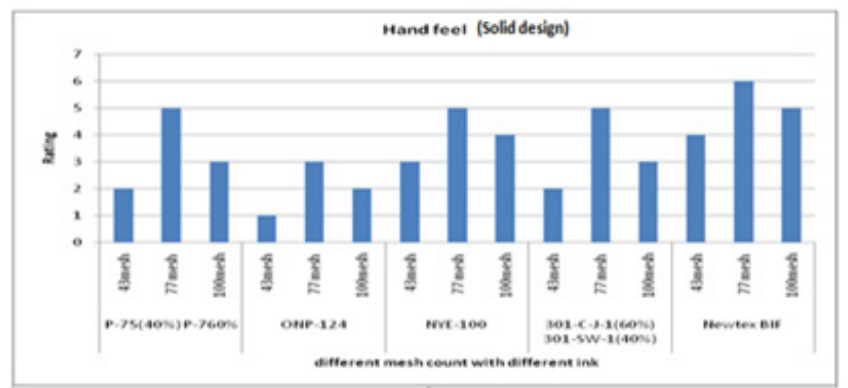

Figure 3 Assessment for hand feel in solid design.

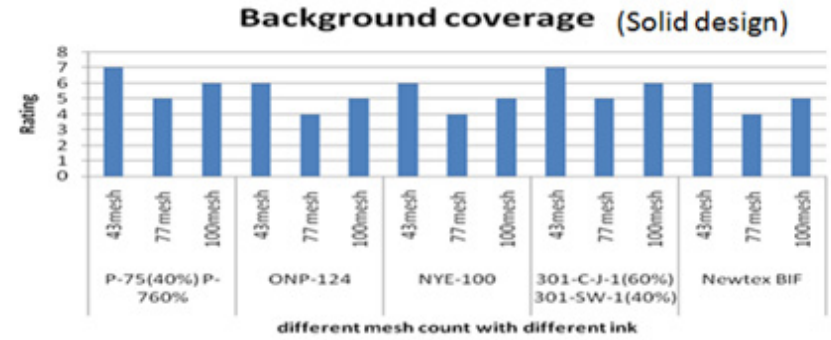

Figure 4 Visual assessment for background coverage in solid design.

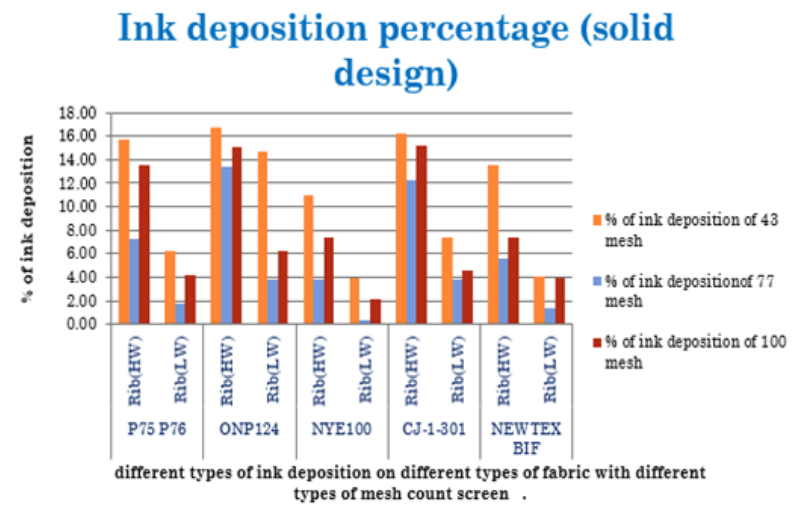

Figure 5 Ink deposition percentage (solid design).

\section{Analysis of solid design under microscope}

For solid design, 43, 77 and 100 mesh count fabric was used as a print screen. In solid design number 4 was selected at the bottom of the image for explanation under the microscopic view in $640 \times 480$-pixel camera size. For finding the printing accuracy, distance 1, distance 2, distance 3 , distance 4 and angle 1, angle 2 was measured in positive and the similar distance and angle was compared in printed fabric by different ink under different mesh count screen. The background coverage was assessed by the open space present in the printed fabric. Outer line sharpness was assessed by the distortion of print ink from the outer line.

P-75 D-76 ink system showed good result. The distance 1, distance 2 , distance 3 , distance 4 were 13.08,8.9,23.44 and 7.1 respectively which were almost the similar distance of the image in positive whose values were 13.48,8.8,23.4 and7.8 consecutively for 100 mesh.

Angle 1 and Angle 2 were found $90^{\circ}$ and $64.8^{\circ}$ which was almost similar like image negative whose values were $90^{\circ}$ and $60.95^{\circ}$ consecutively for100 mesh. The outer line sharpness was good in 100 mesh count and background coverage was also good (Figure 6).
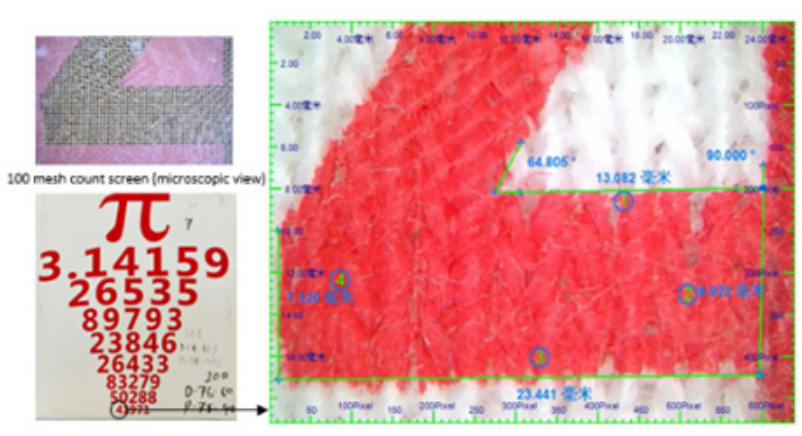

Printed fabric (normal view)

Printed fabric (microscopic view)

Figure 6 Image of solid design printed fabric using 100 mesh count screen $(640 \times 480$ pixels).

From Figure 7, the printed fabric by the 77 mesh count screen showed poor accuracy and back ground coverage was not good. On the otherhand, in Figure 8, printed fabric by the 43 mesh count screen showed very poor accuracy in line sharpness but able to hide the background.
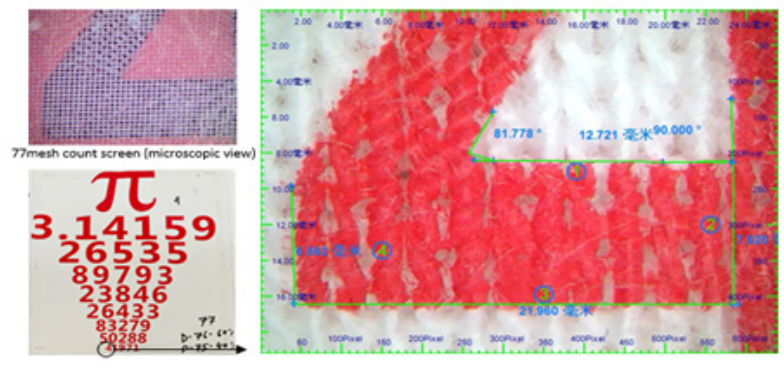

Printed fabric (normal view)

Printed fabric (microscopic view)

Figure 7 Image of solid design printed fabric using 77 mesh count screen $(640 \times 480$ pixels $)$.

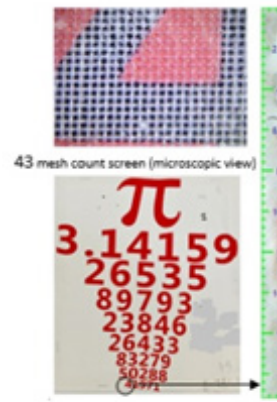

Printed fabric (normal view)

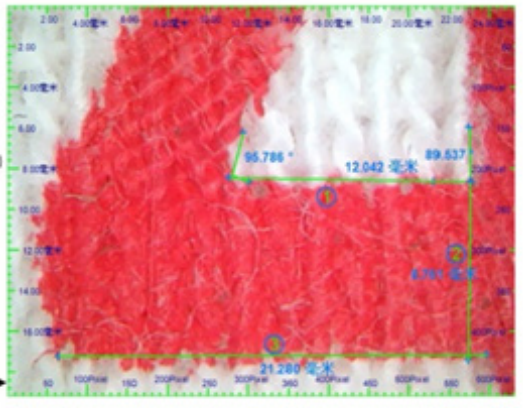

Printed fabric (microscopic view)
Figure 8 Image of solid design printed fabric using 43 mesh count screen $(640 \times 480$ pixels).

Form Table 6, the percentage of opening areas was $27.34 \%, 15.75 \%$ and $14.04 \%$ at 43,100 and 77 mesh count respectively and the order of mesh opening was found $43>100>77$. The printed fabric by 100 mesh count screen showed high accuracy and sharpness of line as the number of open area were higher (144) and single open area had lower area $\left(0.0394 \mathrm{~mm}^{2}\right)$ than 77 mesh count but total background coverage area was lower. In 77 mesh count the number of open rectangles was 64 and single rectangle was $0.0509 \mathrm{~mm}^{2}$. So, in 77 mesh count the accuracy were lower and coverage were higher than 100 mesh count because of being number of open area and total open area were less at 77 mesh count than 100 mesh count. 
The open area of 43 mesh (for single rectangle) was $0.3938 \mathrm{~mm}^{2}$ and yarn width was $0.488 \mathrm{~mm}$. The large open area was able to cover self-open area and the adjacent portion of the closed area by taking more paste but it lost the accuracy. When line was angled, saw tooth effect was seen. Inter lacing of yarn caused a triangle closed area which caused successive missing of printing. This triangle area was greater in 43 mesh count screen. So saw tooth effect was prominent at printed fabric by 43 mesh screen (Figure 8 ). The saw tooth prominence order was 43 mesh count screen $>77$ mesh count screen. The saw tooth effect was not visible at printed fabric by 100 mesh count screen (Figure 9) (Figure 10).

From Table 8, it was found that accuracy of printing was better for higher mesh count with lower opening area by different ink deposition.

Table 8 Different distance and angle measurement in solid design Printed fabric with different ink

\begin{tabular}{|c|c|c|c|c|c|c|c|c|c|}
\hline $\begin{array}{l}\text { Design: Solid } \\
\text { Positive(Image) }\end{array}$ & $\begin{array}{l}\text { Distancel } \\
(\mathrm{mm})\end{array}$ & $\begin{array}{l}\text { Distance2 } \\
(\mathrm{mm})\end{array}$ & $\begin{array}{l}\text { Distance3 } \\
(\mathrm{mm})\end{array}$ & $\begin{array}{l}\text { Distance4 } \\
(\mathrm{mm})\end{array}$ & $\begin{array}{l}\text { Angle I } \\
\text { (degree) }\end{array}$ & $\begin{array}{l}\text { Angle2 } \\
\text { (degree) }\end{array}$ & Visible Area & & \\
\hline & $|3.48|$ & 8.8 & 23.4 & 7.8 & 90 & 60.95 & $100 \%$ Covered & & \\
\hline Ink Name & Mesh count & $\begin{array}{l}\text { Distancel } \\
(\mathrm{mm})\end{array}$ & $\begin{array}{l}\text { Distance2 } \\
(\mathrm{mm})\end{array}$ & $\begin{array}{l}\text { Distance3 } \\
(\mathrm{mm})\end{array}$ & $\begin{array}{l}\text { Distance4 } \\
(\mathrm{mm})\end{array}$ & & $\begin{array}{l}\text { Angle I } \\
\text { (in deg) }\end{array}$ & $\begin{array}{l}\text { Angle2 } \\
\text { (in deg) }\end{array}$ & Visible Area \\
\hline P-75(40\%) & 43 & 12.042 & 9.761 & 20.28 & - & & 89.5 & 95.7 & Very LittleVisible \\
\hline \multirow[t]{2}{*}{ P-76(60\%) } & 77 & 12.72 & 7.92 & 21.96 & 6.562 & & 90 & 81 & Visible \\
\hline & 100 & 13.08 & 8.9 & 23.44 & 7.1 & & 90 & 64.8 & LittleVisible \\
\hline \multirow[t]{3}{*}{ ONP-I 24} & 43 & 13.3 & 8.7 & 22.24 & 8.6 & & 8.5 & 57 & LittleVisible \\
\hline & 77 & 12.88 & 8.7 & 20.88 & 6.6 & & 90 & 80 & MoreVisible \\
\hline & 100 & 12.28 & 9.2 & 22.76 & 7.4 & & 90 & 68.6 & Visible \\
\hline \multirow[t]{3}{*}{ NYE-I00 } & 43 & $10.72 \mid$ & 10.24 & 21.06 & 7.9 & & 104.2 & 66.61 & Very LittleVisible \\
\hline & 77 & $|2.92|$ & 8.52 & 22.16 & 5.9 & & 94.6 & 74.76 & Visible \\
\hline & 100 & 11.813 & 9.28 & 22.08 & 7.4 & & 93 & 77 & Visible \\
\hline $30 I-C-J-I$ & 43 & II.226 & 8.9 & 20.2 & 6.7 & 91.2 & & 67.5 & Little Visible \\
\hline \multirow[t]{2}{*}{ 30I-SW-I } & 77 & 12.6 & 8.76 & 22.1 & 6.64 & 98.4 & & 65.8 & MoreVisible \\
\hline & 100 & 13 & 9.2 & 23 & 6.2 & 92 & & 54 & Visible \\
\hline \multirow[t]{3}{*}{ NewtexBIF } & 43 & 12.16 & 8.7 & 22.6 & 7.44 & 102 & & 64.5 & Little Visible \\
\hline & 77 & 13.8 & 8.4 & 22.8 & 7.6 & 99.3 & & 67.13 & Visible \\
\hline & 100 & 13 & 8.8 & 22.24 & 7.36 & 90 & & 59.34 & Visible \\
\hline
\end{tabular}

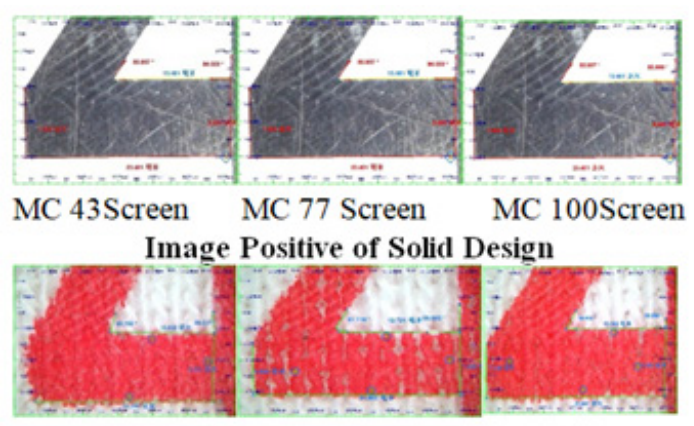

Printed Fabric by using ink P-75(40\%) P-76 $60 \%)$

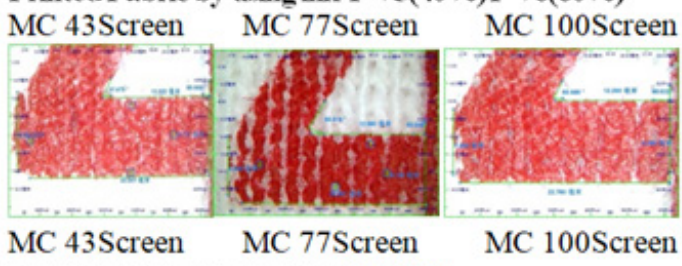
Printed Fabric by using ink ONP124

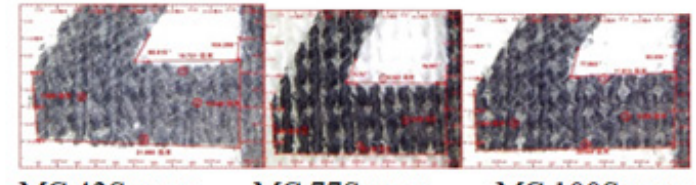

MC 43Screen MC 77Screen MC 100Screen Printed Fabric by using ink NYE-100

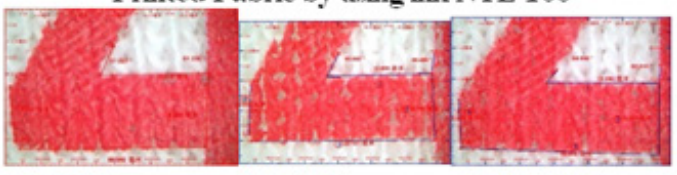

MC 43Screen MC 77Screen MC 100Screen Pinted Fabric by using ink 301-C-J-1 $(60 \%)$ 301-SW-1 $(40 \%)$

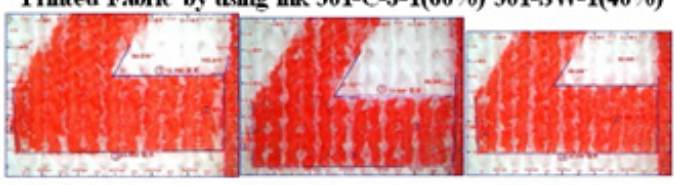

MC 43Screen MC 77Screen MC 100Screen Printed Fabric by using ink NEWTEX BIF

Figure 9 Printed fabric for solid deign under microscope (640×480 pixels). 


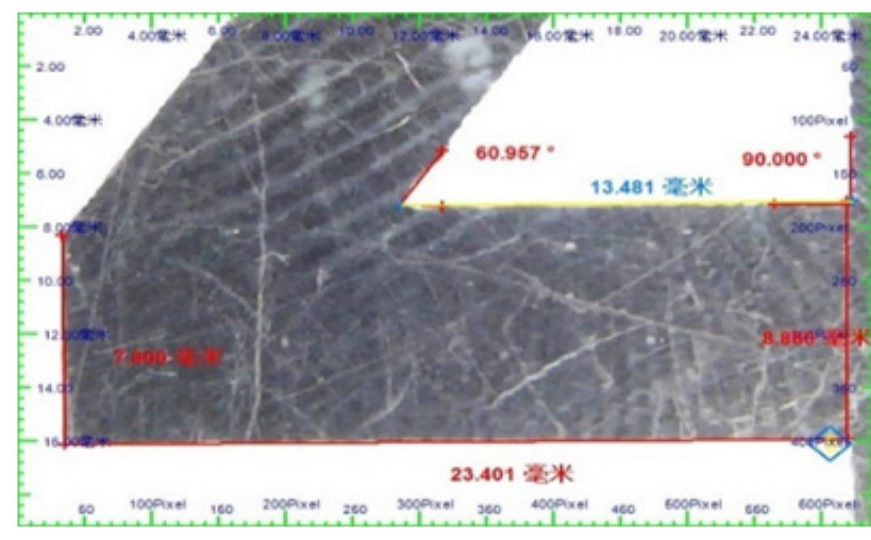

Figure 10 Image positive of solid design $(640 \times 480$ pixels $)$.

From Figure 11, internal distance was decreased and external distance was increased in low mesh count. Distance 1, distance 2, distance 3 and distance 4 were nearer in printed fabric with high mesh count with compare to image positive. From Figure 12, Angle1 was larger in printed fabric with 43 count screen and nearer in printed fabric with high mesh count with compare to image positive.

\section{Different distance comparision with image positive and printed} fabric

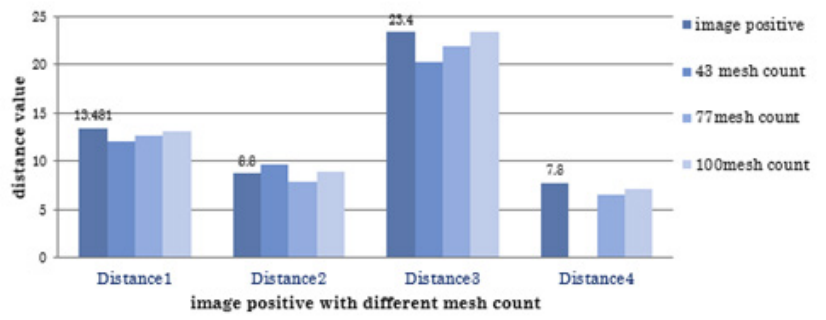

Figure II Different distance comparison with image positive and printed fabric.

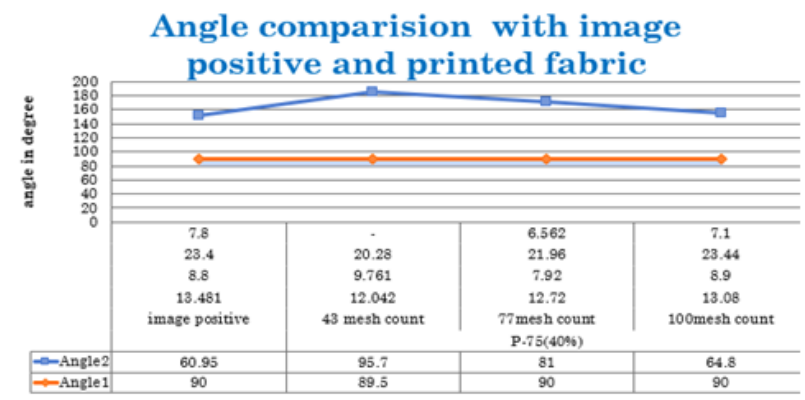

Figure 12 Angle comparison with image positive and printed fabric.

\section{Color fastness performance}

Washing Fastness and light fastness test of different printed fabric under different mesh count with different ink was done.

Washing fastness: There was no significant change of wash fastness with the change of mesh count (Figure 13).

Light Fastness: There was no significant change of light fastness with the change of mesh count (Figure 14).

\section{WASHING FASTNESS}

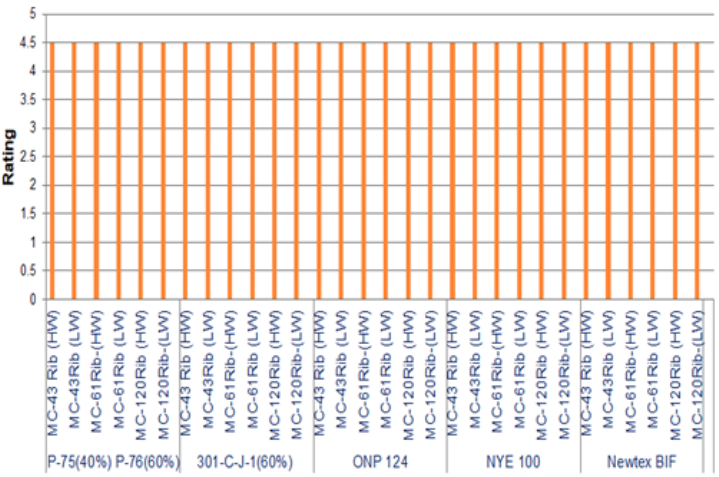

Different mesh count with different fabric and ink

Figure I 3 Washing Fastness of different printed fabric under different mesh count with different ink.

\section{LIGHT FASTNESS}

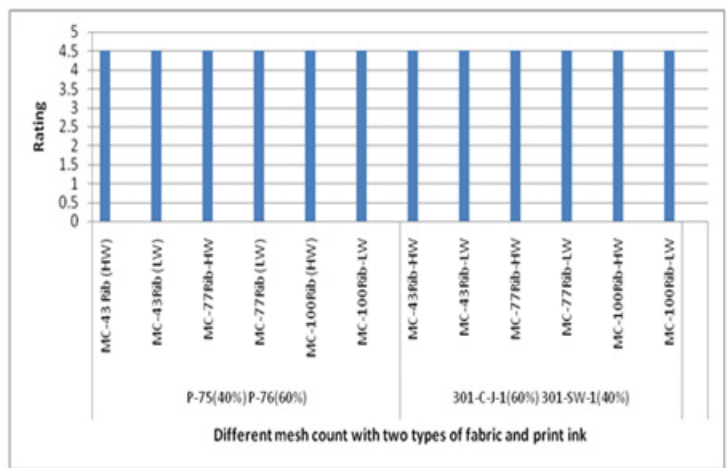

Figure I4 Light Fastness of different printed fabric under different mesh count with different.

\section{Conclusion}

The thesis work was done to find the mesh opening effect on the solid design of knit cotton printed fabric. The mesh opening area was calculated to find the amount of ink passed through, level of print detail in the solid design. Thread diameter of mesh yarn has a great impact on mesh opening. Mesh opening can be higher in higher mesh count screen than lower mesh count screen depending on the thread diameter of mesh fabric.

It was found that more ink was deposited on high GSM fabric than the lower GSM fabric and percentage of ink deposition was greater for high viscous paste than lower viscous paste.

The lower mesh opening screen was capable of giving a better hand feel in cotton printed fabric than higher mesh opening screen depending on types of inks.

It was found that the higher mesh opening area results in good background coverage in printed fabric. The saw-tooth effect was prominent in the higher mesh opening screen.

Print detail was not good in the higher mesh opening screen. The accuracy in line size and sharpness was nearer to image positive in lower mesh opening screen. 
Finally, the lower mesh opening screen was capable of giving high accuracy in design with lower ink consumption and good hand feel. On the contrary, higher mesh opening screen was capable of giving good background coverage, but lost accuracy in print detail and line sharpness.

There was no change in color fastness performance of printed fabric with the change of mesh count.

\section{Acknowledgments}

I would like to express my gratitude to Orient-Chem Ltd., DysinChem Ltd. \& Dysin International Ltd for their valuable and cordial support in various aspects of the thesis work.

\section{Funding}

None.

\section{Conflicts of interest}

The authors declare that there is no conflict of interest in publishing articles.

\section{References}

1. Handbook for screen printers, Sefar Inc. Printing Division, Switzerland; 1999. $11 \mathrm{p}$.

2. Handbook for screen printers, Sefar Inc. Printing Division, CH-9425, Thal/SG, Switzerland; 1999.

3. https://oecotextiles.wordpress.com/tag/plastisol-ink/

4. Leslie W C Miles. Textile printing, second edition, $21 \mathrm{p}$.

5. Leslie W C Miles. Textile printing. second edition, pp: 44-45.

6. ISO 105-C02.Textiles: test for color fastness part C02, Color Fastness to washing. 1994.

7. ISO 105-B02.Test for color fastness to artificial light. 1994. 